\title{
Computational Analysis of a Series of Chlorinated Chalcone Derivatives
}

\author{
Bradley 0. Ashburn \\ Mathematics, Natural, and Health Sciences Division, University of Hawai'i-West O'ahu, Kapolei, HI, US \\ Email: bashburn@hawaii.edu
}

How to cite this paper: Ashburn, B.O. (2019) Computational Analysis of a Series of Chlorinated Chalcone Derivatives. Computational Chemistry, 7, 106-120. https://doi.org/10.4236/cc.2019.74008

Received: September 24, 2019

Accepted: October 13, 2019

Published: October 16, 2019

Copyright $\odot 2019$ by author(s) and Scientific Research Publishing Inc. This work is licensed under the Creative Commons Attribution International License (CC BY 4.0).

http://creativecommons.org/licenses/by/4.0/

\begin{abstract}
A systematic conceptual density functional theory (DFT) analysis was performed on a series of chlorinated chalcones to study the effect of electron distribution on antimicrobial activity. In our previous work, a series of 16 chlorinated chalcones were synthesized to determine the antimicrobial effects of varying the location of the halogen substituent on each aromatic ring of the chalcone. Herein is reported a DFT investigation of those 16 chalcones and a comparison of quantum chemical properties to their antimicrobial activity. DFT global chemical reactivity descriptors (chemical hardness/softness, chemical potential/electronegativity, and electrophilicity) and local reactivity descriptors (Fukui functions and dual descriptor) were calculated for all compounds using Spartan'18 software. All calculations were carried out at the B3LYP/6-31G* level of theory. Reactivity analysis of the Fukui dual descriptor calculations reveals sites of nucleophilic and electrophilic attack. These in-silico results provide a foundation for further synthetic optimization of the chalcone skeleton to serve as novel antimicrobial agents.
\end{abstract}

\section{Keywords}

Density Functional Theory, Computational Analysis, In-Silico, Chalcone

\section{Introduction}

Treatment of bacterial infection is a major health issue, with increasing emergence of drug-resistant microbes resulting in two million infections and over twenty thousand deaths each year in the United States alone [1]. Thus, it is crucial to develop new antibiotics to combat these pathogens. Chalcones, of the flavonoid family, are characterized by their dual aromatic rings and $\alpha, \beta$-unsaturated ketone moiety which is responsible for their widely known antimicrobial activities [2]-[10]. In addition to antimicrobial activity, chalcones have been shown to 
exhibit a multitude of other pharmacological effects including, but not limited to, antioxidant [11] [12], anti-inflammatory [13] [14] [15], and antitumor [16] [17] [18] [19]. Synthesis and biological evaluation of chlorine positioning were previously studied in our laboratory [10]. To further the understanding of halogen placement on biological activity, an in-silico analysis can be employed.

Density Functional Theory (DFT) has been shown to elucidate valuable descriptions of chemical reactivity, molecular structure, vibrational frequencies, and the energetics of chemical reactions [20] [21] [22] [23] [24]. DFT has produced powerful tools for the study of organic reactivity via the use of theoretical global and local reactivity indices and is widely utilized by researchers in chemistry, physics and materials science due to the development of accurate density functionals. Novel DFT studies routinely provide insights into chemical reactivity [24] [25] but no such studies have been performed on chlorinated chalcones. The goal of this computational analysis is to investigate the electronic properties of a series of 16 chalcones and compare them to their previously reported antimicrobial activity.

\section{Materials and Methods}

\subsection{Computational Details}

Quantum chemical calculations were performed using Spartan'18 computational software on a Macintosh computer. Geometry optimization and single point energy calculations were carried out at the B3LYP/6-31G* level of theory and verified by the absence of any imaginary frequencies.

\subsection{Global Quantum Chemical Descriptors}

\subsubsection{Electronic Chemical Potential $(\mu)$ and Mulliken Electronegativity $(x)$}

The electronic chemical potential $(\mu)$ of a molecule is the change in energy with respect to the number of electrons $(N)$ at a fixed external potential $v(r)$ [27] [28]. This represents the tendency of electrons to escape from an atom or molecule.

$$
\mu=\left(\frac{\partial E}{\partial N}\right)_{v(r)}
$$

Application of the finite difference approximation yields the simplified expression:

$$
\mu \approx-\frac{(I P+E A)}{2}
$$

where $I P$ represents the first ionization potential and $E A$ represents the electron affinity of an atom or molecule. The Koopman theorem [29] and Kohn-Sham formalism [30] show that the ionization potential (IP) can be approximated by the energy of the highest occupied molecular orbital $\left(-E_{\text {номо }}\right)$ and the electron affinity $(E A)$ can be approximated by the energy of the lowest unoccupied mo- 
lecular orbital $\left(-E_{L U M O}\right)$

$$
\mu \approx \frac{\left(E_{\text {НОМО }}+E_{\text {LUMO }}\right)}{2}
$$

Given that electronegativity $(\chi)$ is characterized as the tendency of an atom to attract electrons, it can be written as the negative of the chemical potential $(\mu)$ :

$$
\chi=-\mu
$$

\subsubsection{Chemical Hardness $(\eta)$ and Softness $(S)$}

The hard and soft acids and bases (HSAB) principle presented by Pearson [30] [31] [32] states that Lewis acids can be classified as either hard or soft [33] and that the most favorable interactions in an acid/base reaction occur between hard/hard or soft/soft pairs. It would thus be beneficial to have a metric that measures the hardness/softness of molecules. Parr defined a quantitative expression for chemical hardness $(\eta)$ as the change in chemical potential $(\mu)$ of a molecule with respect to the number of electrons $(N)$ at a fixed external potential $v(r)$. This represents the resistance of a molecule to exchange electron density with the environment.

$$
\eta=\left(\frac{\partial \mu}{\partial N}\right)_{v(r)}
$$

Using the finite difference approximation and substituting the ionization potential $(I P)$ for $-E_{\text {Номо }}$ and electron affinity $(E A)$ for $-E_{L U M O}$ the chemical hardness can be expressed as:

$$
\eta \approx \frac{(I P-E A)}{2} \approx \frac{\left(E_{\text {LUMO }}-E_{\text {НОМО }}\right)}{2}
$$

Chemical softness $(S)$ is the reciprocal of chemical hardness $(\eta)$ :

$$
S=\frac{1}{\eta}
$$

\subsubsection{Electrophilicity Index $(\omega)$}

Maynard [34] and Parr [35] defined the electrophilicity index ( $\omega)$ as the tendency of an electrophile to acquire more electron density (chemical potential) divided by the resistance to exchange electron density with the environment (chemical hardness). It is a quantitative value intrinsic to a molecule and has become a powerful tool to predict reactivity.

$$
\omega=\frac{\mu^{2}}{2 \eta}
$$

\subsection{Local Quantum Chemical Descriptors}

\section{Fukui Functions and Dual Descriptor}

The Fukui function $f(r)$ represents the change in electron density at point $r$ with respect to the change in the number of electrons $N$ at a fixed external potential $v(r)$ [36]: 


$$
f(r)=\left(\frac{\partial \rho(r)}{\partial N}\right)_{v(r)}
$$

Parr expanded the use of the Fukui function to show localized areas of nucleophilicity $\left(f^{+}\right)$and electrophilicity $\left(f^{-}\right)$called the condensed Fukui functions [37] [38].

$$
f^{+}(r) \approx \rho_{N+1}(r)-\rho_{N}(r)
$$

and

$$
f^{-}(r) \approx \rho_{N}(r)-\rho_{N-1}(r)
$$

where $\rho_{N}, \rho_{N-1}$, and $\rho_{N+1}$ are the atomic charges in the neutral, anionic and cationic species, respectively.

Combining the two functions provides the most useful description in what is known as the dual descriptor [39] [40] [41]. Where $\Delta f_{k}(r)<0$ represents an atom $k$ of a molecule that is electrophilic and $\Delta f_{k}(r)>0$ an atom $k$ that is nucleophilic.

$$
\Delta f(r)=\left(\frac{\partial f(r)}{\partial N}\right)_{v(r)}
$$

A condensed form is represented by:

$$
\Delta f(r)=f_{k}^{+}-f_{k}^{-}
$$

\section{Results and Discussion}

Chalcones 1a-d, 2a-d, 3a-d, and 4a-d were previously synthesized and tested for antimicrobial activity in our laboratory [10] using agar well diffusion assay by measuring the zones of inhibition against pathogenic bacteria (Escherichia coli, Pseudomonas aeruginosa, and Staphylococcus aureus). The results show that nearly all the chlorinated chalcones synthesized display antibacterial activity comparable to the known antibiotic sulfanilamide. The 16 chalcones, shown in Figure 1 below, vary the positioning of chlorine substituents on each ring of the chalcone skeleton. In order to probe the chemical rationale for the differences in biological activity, each chalcone was analyzed computationally.

Full unconstrained molecular geometry optimizations of 16 chalcones were carried out using Wavefunction Spartan'18 software [42] using the exchange correlation functional by Becke [43] with gradient-corrected correlation provided by Lee, Yang and Parr [44] with the $6-31 G^{*}$ basis set. This DFT method was chosen since it is fast, less computationally intensive, takes electron correlation into account, and provides accuracy in reproducing experimental data [45]. Optimized geometries depicting the molecular structures of the most stable forms of each chalcone were confirmed by vibrational analysis calculations and characterized as minima in their potential energy surface via the absence of an imaginary frequency. 

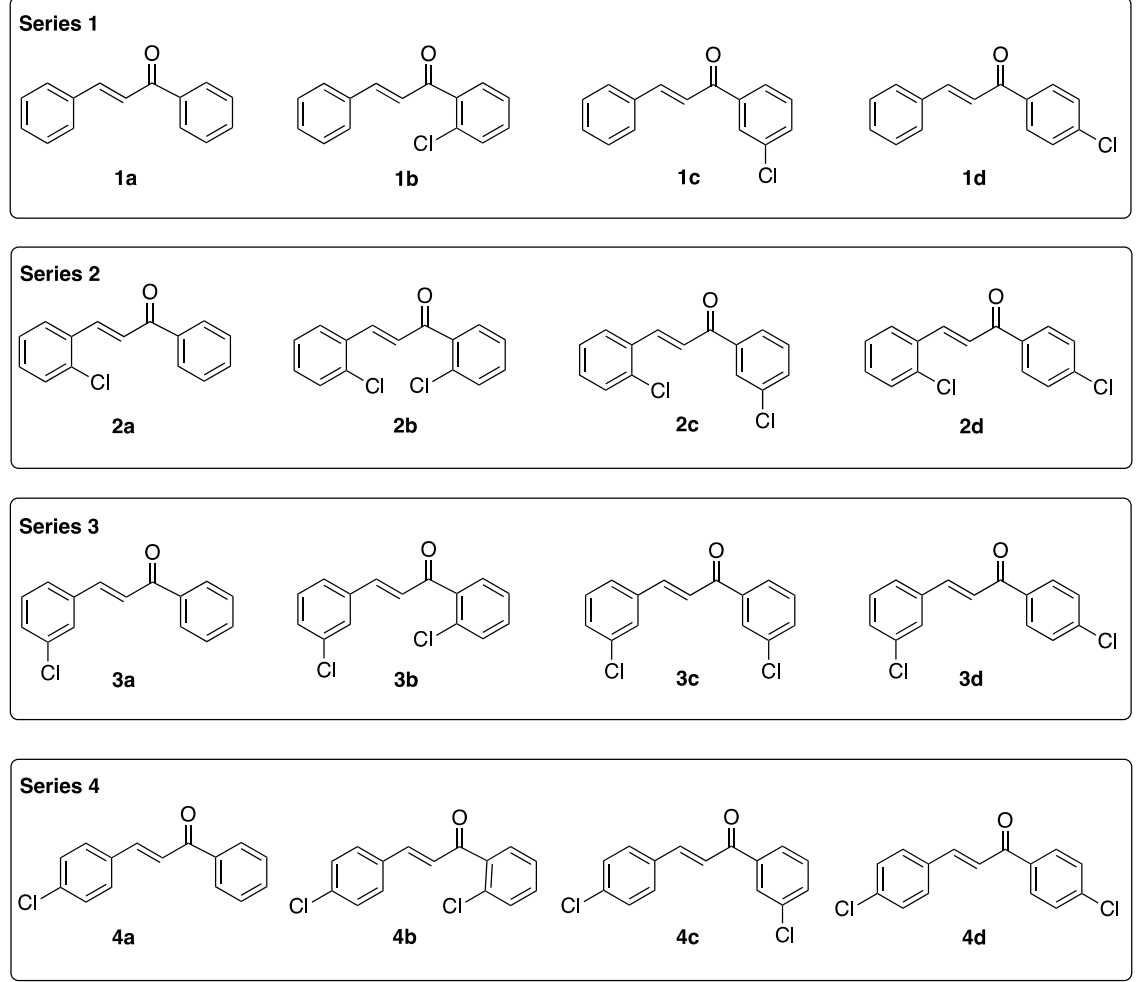

Figure 1. Structures of 16 chalcones with varying chlorine substitution patterns.

Visualization of the contour plots of the Highest Occupied Molecular Orbital (HOMO) and Lowest Unoccupied Molecular Orbital (LUMO) are shown in Figures 2-5. Analysis of the frontier molecular orbitals provides valuable information regarding nodal patterns and individual atom contributions.

The largest HOMO-LUMO energy gaps are occurring in chalcones $\mathbf{1 b}, \mathbf{2} \mathbf{b}, \mathbf{3 b}$, $4 a$, and $4 \mathbf{b}$, four of which have a chlorine substituent in the 2 '-position. The largest energy gap average was in Series 3, where a chlorine is in the 3-position. Chalcone $3 b$ has the highest HOMO-LUMO energy gap of all 16 chalcones.

Tables 1-4 show the global chemical reactivity descriptors and the $\log P$ for each series of chalcones. The partition coefficient of a compound is a widely used metric for determining lipophilicity, which is useful for identifying compounds which may have similar likeness to drugs and possible interaction with biological macromolecules such as receptors and enzymes [46]. Lipophilicity is an important physicochemical property of a potential drug as it describes solubility, absorption, membrane penetration, distribution, and excretion. The partition coefficient is the quotient of the concentration of the compound in a lipophilic solvent (typically 1-octanol) and the concentration of the compound in water. The logarithm of the partition coefficient is referred to as $\log P$. A positive value for $\log P$ means the compound is more lipophilic, whereas a negative value means the compound is more hydrophilic.

The electrophilicity value $(\omega)$ holds significant interest due to the enone moiety's susceptibility to nucleophilic attack. Series 4 contained the most electrophilic 

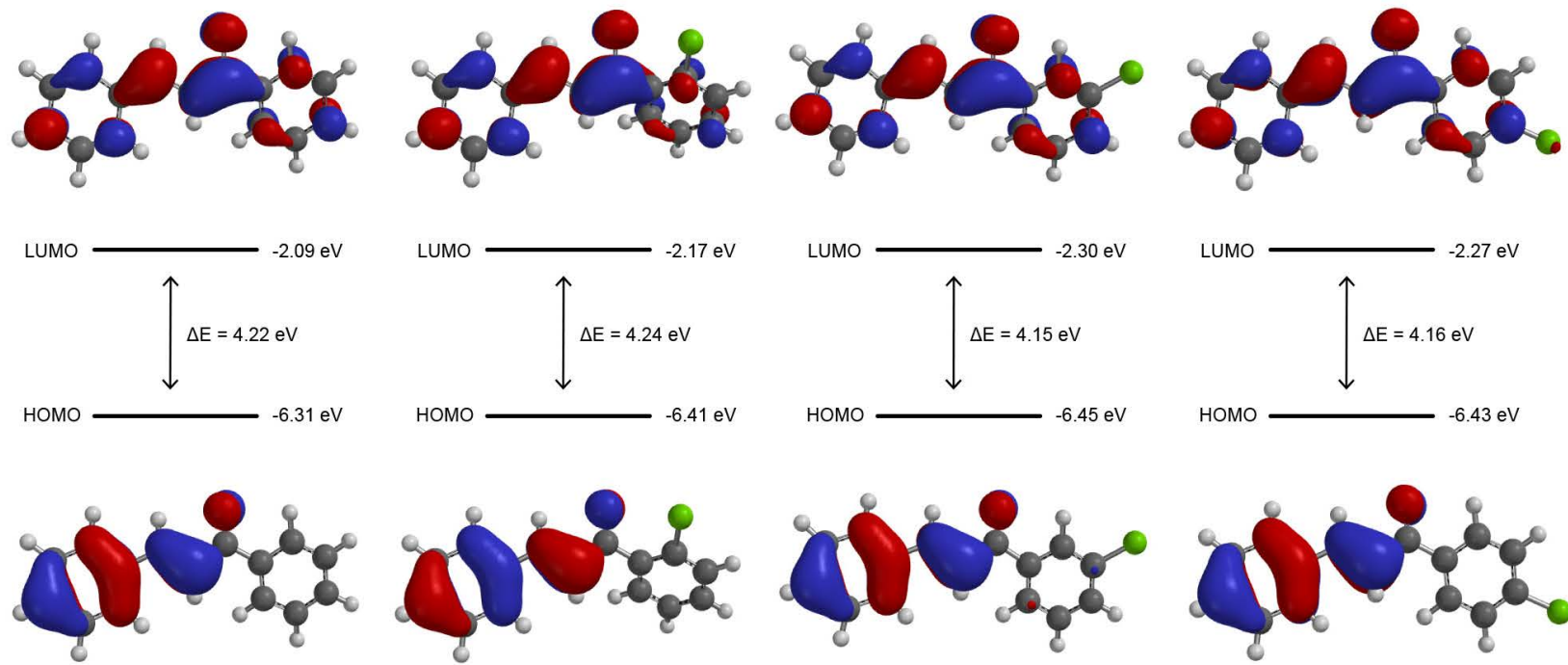

1a

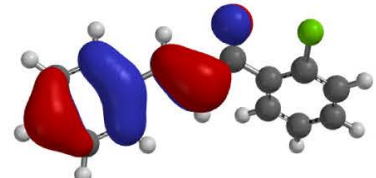

$1 b$

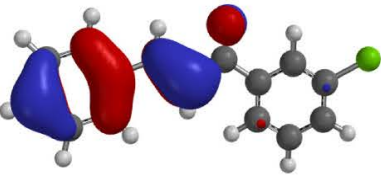

1c

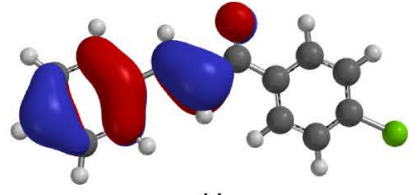

$1 d$

Figure 2. Frontier molecular orbitals of chalcone series 1 .
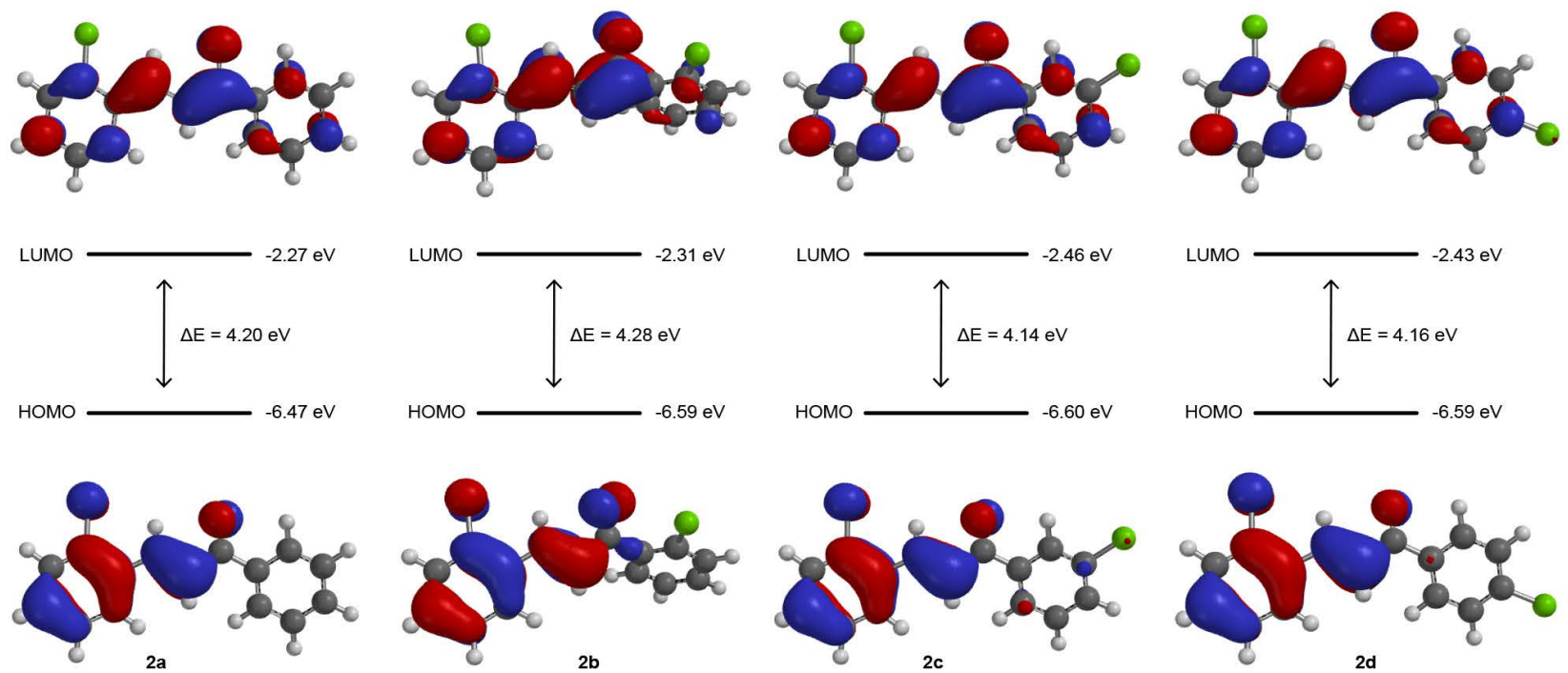

Figure 3. Frontier molecular orbitals of chalcone series 2.

chalcones. It is also notable that Series 4 chalcones were the softest as well. The most electrophilic chalcone overall was $3 \mathrm{c}$ however.

All dichlorinated chalcones had the same $\log P$ values, as did the three monosubstituted chlorinated chalcones. Adding chlorine atoms (from zero to two) increases $\log P$ regardless of the positioning on the aromatic rings. Higher $\log P$ values represent greater lipophilicity. This was evidenced experimentally by decreased water solubility during biological evaluation. All 16 chalcones did maintain $\log P$ values less than 5 which, according to Lipinski's Rule of 5 , is desirable for molecules to be considered drug-like [47] [48].

Tables 5-8 show the natural bond orbital charge, $f^{+}$value, $f^{-}$value, and the dual descriptor $(\Delta f)$ value calculated for the three carbons comprising the 

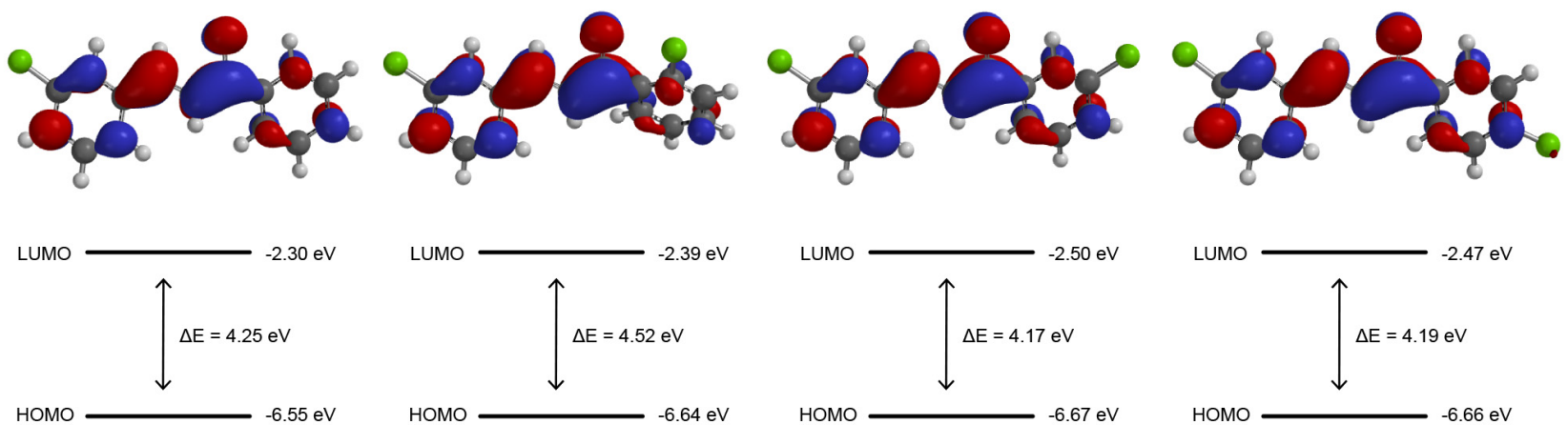

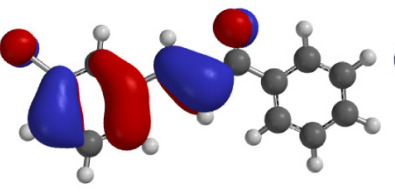

$3 a$

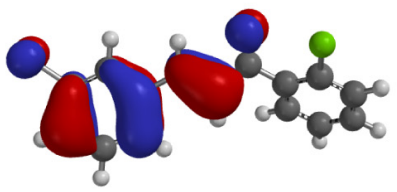

3b

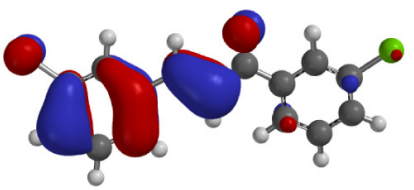

$3 c$

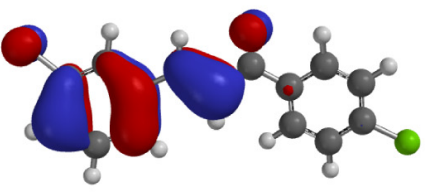

Figure 4. Frontier molecular orbitals of chalcone series 3.
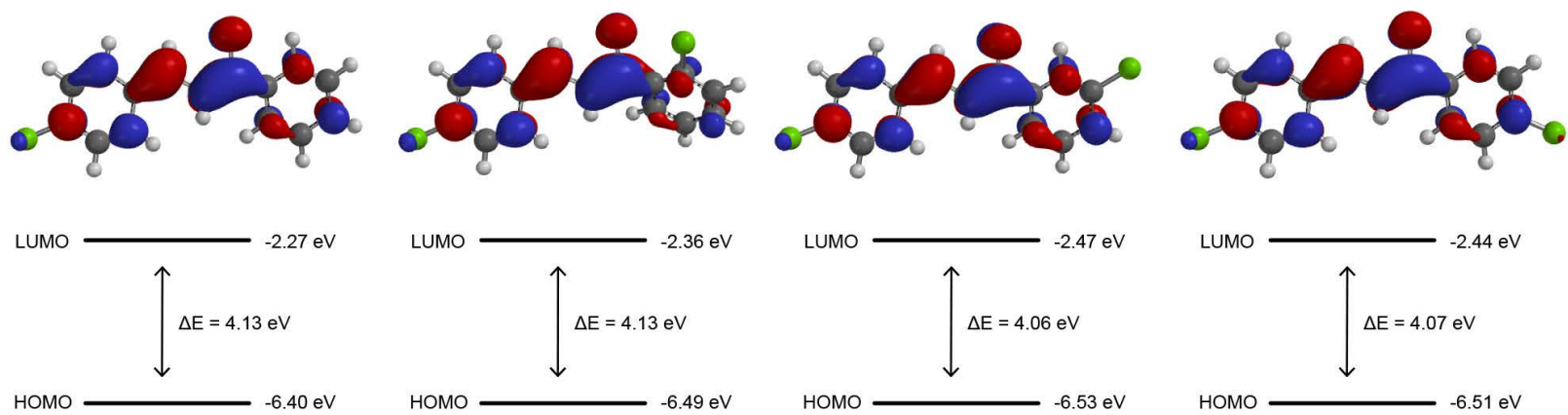

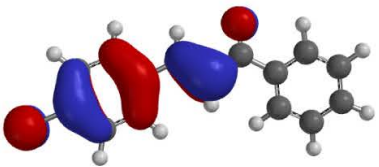

$4 a$

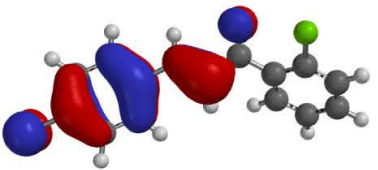

4b

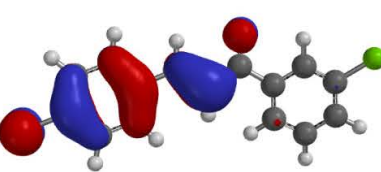

$4 c$

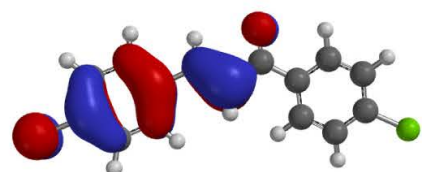

4d

Figure 5. Frontier molecular orbitals of chalcone series 4 .

Table 1. Global reactivity indicators for chalcone series 1.

\begin{tabular}{ccccc}
\hline Reactivity & \multicolumn{4}{c}{ B3LYP/6-31G } \\
Index & $\mathbf{1 a}$ & $\mathbf{1 b}$ & $\mathbf{1} \mathbf{c}$ & $\mathbf{1 d}$ \\
\cline { 2 - 5 }$E_{\text {HOMO }}(\mathrm{eV})$ & -6.31 & -6.41 & -6.45 & -6.43 \\
$E_{\text {LUMO }}(\mathrm{eV})$ & -2.09 & -2.17 & -2.30 & -2.27 \\
$E_{\text {Gap }}(\mathrm{eV})$ & 4.22 & 4.24 & 4.15 & 4.16 \\
$\mu(\mathrm{eV})$ & -4.20 & -4.29 & -4.38 & -4.35 \\
$\chi(\mathrm{eV})$ & 4.20 & 4.29 & 4.38 & 4.35 \\
$\eta(\mathrm{eV})$ & 2.11 & 2.12 & 2.08 & 2.08 \\
$S(\mathrm{eV}-1)$ & 0.474 & 0.472 & 0.481 & 0.481 \\
$\omega(\mathrm{eV})$ & 4.18 & 4.34 & 4.61 & 4.55 \\
$\log P$ & 3.76 & 4.32 & 4.32 & 4.32 \\
\hline
\end{tabular}


Table 2. Global reactivity indicators for chalcone series 2 .

\begin{tabular}{|c|c|c|c|c|}
\hline \multirow{2}{*}{$\begin{array}{l}\text { Reactivity } \\
\text { Index }\end{array}$} & \multicolumn{4}{|c|}{ B3LYP/6-31G* } \\
\hline & $2 a$ & $2 b$ & $2 c$ & $2 d$ \\
\hline$E_{\text {Номо }}(\mathrm{eV})$ & -6.47 & -6.59 & -6.60 & -6.59 \\
\hline$E_{L U M O}(\mathrm{eV})$ & -2.27 & -2.31 & -2.46 & -2.43 \\
\hline$E_{G a p}(\mathrm{eV})$ & 4.20 & 4.28 & 4.14 & 4.16 \\
\hline$\mu(\mathrm{eV})$ & -4.37 & -4.45 & -4.53 & -4.51 \\
\hline$\chi(\mathrm{eV})$ & 4.37 & 4.45 & 4.53 & 4.51 \\
\hline$\eta(\mathrm{eV})$ & 2.10 & 2.14 & 2.07 & 2.08 \\
\hline$S\left(\mathrm{eV}^{-1}\right)$ & 0.476 & 0.467 & 0.483 & 0.481 \\
\hline$\omega(\mathrm{eV})$ & 4.55 & 4.63 & 4.96 & 4.89 \\
\hline $\log P$ & 4.32 & 4.88 & 4.88 & 4.88 \\
\hline
\end{tabular}

Table 3. Global reactivity indicators for chalcone series 3.

\begin{tabular}{ccccc}
\hline \multirow{2}{*}{$\begin{array}{c}\text { Reactivity } \\
\text { Index }\end{array}$} & $3 \mathrm{a}$ & $3 \mathrm{~b}$ & $3 \mathrm{c}$ & $3 \mathrm{~d}$ \\
\cline { 2 - 5 } & -6.55 & -6.64 & -6.67 & -6.66 \\
$E_{\text {HOMO }}(\mathrm{eV})$ & -2.30 & -2.39 & -2.50 & -2.47 \\
$E_{L U M O}(\mathrm{eV})$ & 4.25 & 4.52 & 4.17 & 4.19 \\
$E_{\text {Gap }}(\mathrm{eV})$ & -4.43 & -4.52 & -4.59 & -4.57 \\
$\mu(\mathrm{eV})$ & 4.43 & 4.52 & 4.59 & 4.57 \\
$\chi(\mathrm{eV})$ & 2.13 & 2.26 & 2.09 & 2.10 \\
$\eta(\mathrm{eV})$ & 0.469 & 0.442 & 0.478 & 0.476 \\
$\left.S(\mathrm{eV})^{-1}\right)$ & 4.61 & 4.52 & 5.04 & 4.97 \\
$\omega(\mathrm{eV})$ & 4.32 & 4.88 & 4.88 & 4.88 \\
$\log P$ & & & \\
\hline
\end{tabular}

Table 4. Global reactivity indicators for chalcone series 4 .

\begin{tabular}{ccccc}
\hline Reactivity & \multicolumn{4}{c}{ B3LYP/6-31G } \\
Index & $4 \mathrm{a}$ & $\mathbf{4 b}$ & $\mathbf{4 c}$ & $\mathbf{4 d}$ \\
\cline { 2 - 4 }$E_{\text {HOMO }}(\mathrm{eV})$ & -6.40 & -6.49 & -6.53 & -6.51 \\
$E_{L U M O}(\mathrm{eV})$ & -2.27 & -2.36 & -2.47 & -2.44 \\
$E_{\text {Gap }}(\mathrm{eV})$ & 4.13 & 4.13 & 4.06 & 4.07 \\
$\mu(\mathrm{eV})$ & -4.34 & -4.43 & -4.50 & -4.48 \\
$\chi(\mathrm{eV})$ & 4.34 & 4.43 & 4.50 & 4.48 \\
$\eta(\mathrm{eV})$ & 2.07 & 2.07 & 2.03 & 2.04 \\
$S(\mathrm{eV})$ & 0.483 & 0.483 & 0.493 & 0.490 \\
$\omega(\mathrm{eV})$ & 4.55 & 4.74 & 4.99 & 4.92 \\
$\log P$ & 4.32 & 4.88 & 4.88 & 4.88 \\
\hline
\end{tabular}


Table 5. Fukui indices for chalcone series 1.

\begin{tabular}{ccccc}
\hline Atom & Charge & $f_{k}^{+}$ & $f_{k}^{-}$ & $\Delta f$ \\
\hline C1 & & Chalcone 1a & & -0.133 \\
C2 & +0.522 & -0.116 & +0.017 & +0.129 \\
C3 & -0.312 & -0.027 & -0.156 & -0.104 \\
\hline & -0.134 & -0.133 & -0.029 & -0.139 \\
\hline C1 & & Chalcone 1b & & +0.105 \\
C2 & +0.526 & -0.118 & +0.021 & -0.117 \\
C3 & -0.325 & -0.034 & -0.139 & \\
\hline & -0.129 & -0.138 & -0.021 & -0.137 \\
\hline C1 & & Chalcone 1c & & +0.121 \\
C2 & +0.523 & -0.118 & +0.019 & -0.110 \\
C3 & -0.316 & -0.017 & -0.138 & -0.111 \\
\hline C2 & -0.128 & -0.135 & -0.025 & -0.149 \\
\hline C1 & -0.129 & -0.134 & -0.023 & +0.032 \\
\hline
\end{tabular}

Table 6. Fukui indices for chalcone series 2.

\begin{tabular}{|c|c|c|c|c|}
\hline Atom & Charge & $f_{k}^{+}$ & $f_{k}^{-}$ & $\Delta f$ \\
\hline \multicolumn{5}{|c|}{ Chalcone 2a } \\
\hline $\mathrm{C} 1$ & +0.522 & -0.107 & +0.013 & -0.120 \\
\hline $\mathrm{C} 2$ & -0.299 & -0.040 & -0.137 & +0.097 \\
\hline $\mathrm{C} 3$ & -0.144 & -0.128 & -0.033 & -0.095 \\
\hline \multicolumn{5}{|c|}{ Chalcone 2b } \\
\hline $\mathrm{C} 1$ & +0.528 & -0.115 & +0.014 & -0.129 \\
\hline $\mathrm{C} 2$ & -0.317 & -0.041 & -0.107 & +0.066 \\
\hline $\mathrm{C} 3$ & -0.137 & -0.136 & -0.024 & -0.112 \\
\hline \multicolumn{5}{|c|}{ Chalcone 2c } \\
\hline $\mathrm{C} 1$ & +0.523 & -0.111 & +0.016 & -0.127 \\
\hline $\mathrm{C} 2$ & -0.304 & -0.028 & -0.123 & +0.095 \\
\hline $\mathrm{C} 3$ & -0.138 & -0.130 & -0.028 & -0.102 \\
\hline \multicolumn{5}{|c|}{ Chalcone $2 \mathrm{~d}$} \\
\hline $\mathrm{C} 1$ & +0.521 & -0.109 & +0.030 & -0.139 \\
\hline $\mathrm{C} 2$ & -0.303 & -0.029 & -0.133 & +0.104 \\
\hline $\mathrm{C} 3$ & -0.139 & -0.130 & -0.026 & -0.104 \\
\hline
\end{tabular}


Table 7. Fukui indices for chalcone series 3.

\begin{tabular}{ccccc}
\hline Atom & Charge & $f_{k}^{+}$ & $f_{k}^{-}$ & $\Delta f$ \\
\hline C1 & +0.523 & -0.111 & +0.012 & -0.123 \\
C2 & -0.303 & -0.037 & -0.127 & +0.090 \\
C3 & -0.139 & -0.127 & -0.031 & -0.096 \\
\hline C1 & & Chalcone 3b $3 \mathrm{~b}$ & & -0.132 \\
C2 & +0.527 & -0.113 & +0.019 & 0.068 \\
C3 & -0.316 & -0.042 & -0.110 & -0.110 \\
\hline C1 & -0.134 & -0.131 & -0.021 & -0.130 \\
C2 & & Chalcone 3c & & +0.085 \\
C3 & -0.524 & -0.114 & +0.016 & -0.104 \\
\hline C3 & -0.307 & -0.027 & -0.112 & -0.103 \\
\hline C1 & -0.133 & -0.130 & -0.026 & -0.142 \\
\hline
\end{tabular}

Table 8. Fukui indices for chalcone series 4 .

\begin{tabular}{|c|c|c|c|c|}
\hline Atom & Charge & $f_{k}^{+}$ & $f_{k}^{-}$ & $\Delta f$ \\
\hline \multicolumn{5}{|c|}{ Chalcone $4 \mathrm{a}$} \\
\hline $\mathrm{C} 1$ & +0.522 & -0.110 & +0.017 & -0.127 \\
\hline $\mathrm{C} 2$ & -0.306 & -0.035 & -0.150 & +0.115 \\
\hline C3 & -0.139 & -0.126 & -0.020 & -0.106 \\
\hline \multicolumn{5}{|c|}{ Chalcone $4 \mathrm{~b}$} \\
\hline $\mathrm{C} 1$ & +0.527 & -0.113 & +0.020 & -0.133 \\
\hline $\mathrm{C} 2$ & -0.320 & -0.041 & -0.128 & +0.087 \\
\hline C3 & -0.134 & -0.131 & -0.013 & -0.118 \\
\hline \multicolumn{5}{|c|}{ Chalcone $4 c$} \\
\hline $\mathrm{C} 1$ & +0.523 & -0.113 & +0.017 & -0.130 \\
\hline $\mathrm{C} 2$ & -0.311 & -0.025 & -0.128 & +0.103 \\
\hline $\mathrm{C} 3$ & -0.133 & -0.129 & -0.017 & -0.112 \\
\hline \multicolumn{5}{|c|}{ Chalcone 4d } \\
\hline $\mathrm{C} 1$ & +0.521 & -0.112 & +0.029 & -0.141 \\
\hline $\mathrm{C} 2$ & -0.310 & -0.026 & -0.138 & +0.112 \\
\hline C3 & -0.134 & -0.128 & -0.015 & -0.113 \\
\hline
\end{tabular}


enone moiety. $\mathrm{C} 1$ is the carbonyl carbon, $\mathrm{C} 2$ is the alpha carbon, and $\mathrm{C} 3$ is the terminal alkene carbon. The natural bond orbital charges were used in Equations (10) and (11) to determine the $f^{+}$and $f^{-}$Fukui indices respectively. The combined values according to equation 13 yields the dual descriptor, where $\Delta f$ is a function that represents the reactivity of the atoms in each molecule.

All 16 chalcones have negative values on $\mathrm{C} 1$ (carbonyl carbon) and C3 (terminal alkene carbon) which follows the logic predicted by modern resonance theory. $\mathrm{C} 1$ had a larger negative value than $\mathrm{C} 3$, representing a higher likelihood for nucleophilic attack to occur there. Chalcone $1 \mathrm{~d}$ had the highest value on $\mathrm{C} 1$ while chalcone $1 \mathrm{~b}$ has the highest value on C3. Chalcone $4 \mathrm{~d}$ had the overall highest values for both atoms.

The four chalcones of Series 4 showed the highest antibacterial activity from our previous testing, with $4 \mathrm{c}$ showing the largest zone of inhibition of all 16 chalcones [10]. From our computational analysis, the chalcones of Series 4 were also the most electrophilic and softest. In addition, chalcone $4 \mathrm{c}$ had the highest averagezone of inhibition when taking into account all three bacterial strains evaluated and was the softest of all 16 chalcones. From these results, it can be determined that increasing electrophilicity and softness are vital for enhancing antimicrobial effectiveness.

Future studies will build on this discovery by synthesizing chalcones substituted in the 4-position and containing substituents that result in greater electrophilic nature. The high values of $\log P$ were also confirmed experimentally with less than ideal solubility in aqueous media. Choosing substituents that will reduce the lipophilicity should result in an enhanced bioavailability.

\section{Conclusion}

Using conceptual DFT, it was determined that chalcones with a chlorine in the 4-position (Series 4) generally contained the most electrophilic and softest chalcones. These were the most active chalcones in previous antimicrobial evaluation. Adding chlorine moieties increases lipophilicity regardless of the positioning, but none of the 16 chalcones exceeded a $\log P$ of 5 . Having a chlorine atom in position 4 of the chalcone skeleton proves to be the most effective location. The results of this study enable further optimization of the chalcone skeleton by retaining the chlorine in position 4 while probing the effects of adding more electrophilic substituents.

\section{Acknowledgements}

The author would like to thank Dr. Helmut Kae, Jonna Amato-Ocampo, and Rina Carrillo for their previous work on this project. The author would also like to thank Leeward Community College for providing the computer software and hardware for this study.

\section{Conflicts of Interest}

The author declares no conflicts of interest regarding the publication of this paper. 


\section{References}

[1] Frieden, T. (2013) Antibiotic Resistance Threats in the United States. Centers for Disease Control and Prevention, Atlanta.

[2] Batovska, D., Parushev, S., Stamboliyska, B., Tsvetkova, I., Ninova, M. and Najdenski, H. (2009) Examination of Growth Inhibitory Properties of Synthetic Chalcones for Which Antibacterial Activity Was Predicted. European Journal of Medicinal Chemistry, 44, 2211-2218. https://doi.org/10.1016/j.ejmech.2008.05.010

[3] Lahtchev, K.L., Batovska, D.I., St. Parushev, P., Ubiyvovk, V.M. and Sibirny, A.A. (2008) Antifungal Activity of Chalcones: A Mechanistic Study Using Various Yeast Strains. European Journal of Medicinal Chemistry, 43, 2220-2228. https://doi.org/10.1016/j.ejmech.2007.12.027

[4] Baviskar, B., Patel, S., Baviskar, B., Khadabadi, S.S. and Shiradkar, M. (2008) Design and Synthesis of Some Novel Chalcones as Potent Antimicrobial Agent. Asian Journal of Research in Chemistry, 1, 67-69.

[5] Prasad, Y., Lakshmana Rao, A. and Rambabu, R. (2008) Synthesis and Antimicrobial Activity of Some Chalcone Derivatives. E-Journal of Chemistry, 5, 461-466. https://doi.org/10.1155/2008/876257

[6] Swamy, P.M. and Agasimundin, Y.S. (2008) Synthesis and Antimicrobial Screening of Certain Substituted Chalcones and Isoxazolines Bearing Hydroxybenzofuran. Rasayan Journal of Chemistry, 1, 421-428.

[7] Kumbhar, D.D., Waghamare, B.Y., Pathade, G.R. and Pardeshi, S.K. (2014) Synthesis and Evaluation of Chalcones as an Anti-Bacterial and Anti-Fungal Agents. Der Pharmacia Lettre, 6, 224-229.

[8] Paramesh, M., Niranjan, M.S., Sarfaraj, N., Shivaraja, S. and Rubbani, M.S. (2010) Synthesis and Antimicrobial Study of Some Chlorine-Containing Chalcones. International Journal of Pharmacy and Pharmaceutical Sciences, 2, 113-117.

[9] Habib, S.I. (2018) Chemical and Biological Potential of Chalcones as a Source of Drug: A Review. International Journal of Pharmacy and Pharmaceutical Research, 11, 104-118.

[10] Amato-Ocampo, J., Carrillo, R., Kae, H. and Ashburn, B.O. (2018) Synthesis and Antimicrobial Evaluation of a Series of Chlorinated Chalcone Derivatives. International Journal of Pharmacy and Pharmaceutical Research, 13, 112-119.

[11] Simirgiotis, M.J., Adachi, S., To, S., Yang, H., Reynertson, K.A., Basile, M.J., Roberto, G.R., Weinstein, I.B. and Kennelly, E.J. (2008) Cytotoxic Chalcones and Antioxidants from the Fruits of Syzygium samarangense (Wax Jambu). Food Chemistry, 107, 813-819. https://doi.org/10.1016/j.foodchem.2007.08.086

[12] Gacche, R.N., Dhole, N.A., Kamble, S.G. and Bandgar, B.P. (2008) In-Vitro Evaluation of Selected Chalcones for Antioxidant Activity. Journal of Enzyme Inhibition and Medicinal Chemistry, 23, 28-31. https://doi.org/10.1080/14756360701306370

[13] Nowakowska, Z. (2007) A Review of Anti-Infective and Anti-Inflammatory Chalcones. European Journal of Medicinal Chemistry, 42, 125-137.

https://doi.org/10.1016/j.ejmech.2006.09.019

[14] Jin, F., Jin, X.Y., Jin, Y.L., Sohn, D.W., Kim, S.A., Sohn, D.H., Kim, Y.C. and Kim, H.S. (2007) Structural Requirements of 2',4',6'-tris(methoxymethoxy) Chalcone Derivatives for Anti-Inflammatory Activity: The Importance of a 2'-Hydroxy Moiety. Archives of Pharmacal Research, 30, 1359-1367.

https://doi.org/10.1007/BF02977357

[15] Zhang, X.W., Zhao, D.H., Quan, Y.C., Sun, L.P., Yin, X.M. and Guan, L.P. (2010) 
Synthesis and Evaluation of Anti-Inflammatory Activity of Substituted Chalcone Derivatives. Medicinal Chemistry Research, 19, 403-412. https://doi.org/10.1007/s00044-009-9202-Z

[16] Lawrence, N.J., Patterson, R.P., Ooi, L.L., Cook, D. and Ducki, S. (2006) Effects of $\alpha$-Substitutions on Structure and Biological Activity of Anticancer Chalcones. Bioorganic \& Medicinal Chemistry Letters, 16, 5844-5848. https://doi.org/10.1016/j.bmcl.2006.08.065

[17] Goniotaki, M., Hatziantoniou, S., Dimas, K., Wagner, M. and Demetzos, C.J. (2004) Encapsulation of Naturally Occurring Flavonoids into Liposomes: Physicochemical Properties and Biological Activity against Human Cancer Cell Lines. Journal of Pharmacy and Pharmacology, 56, 1217-1224. https://doi.org/10.1211/0022357044382

[18] Modzelewska, A., Pettit, C., Achanta, G., Davidson, N.E., Huang, P. and Khan, S.R. (2006) Anticancer Activities of Novel Chalcone and Bis-Chalcone Derivatives. Bioorganic \& Medicinal Chemistry, 14, 3491-3495. https://doi.org/10.1016/j.bmc.2006.01.003

[19] Apalangya, V.A., Bakupog, T., Tutson, C., Sefadzi, S., Early, B., Troy, R.M., Curry, M.L., Robinson, P.M.L., Powell, N.L. and Russell, A.E. (2012) Inhibition of MDAMB-231 Breast Cancer Cell Proliferation by Simple Diphenyl Chalcone and Its Chlorinated Derivative. Research \& Reviews. Journal of Oncology and Hematology, 1,7 .

[20] Parr, R.G. and Yang, W. (1989) Density-Functional Theory of Atoms and Molecules. Oxford University Press, Oxford.

[21] Kohn, W. and Sham, L.J. (1965) Self-Consistent Equations Including Exchange and Correlation Effects. Physical Review, 140, 1133-1138. https://doi.org/10.1103/PhysRev.140.A1133

[22] Becke, A.D. (1997) Density-Functional Thermochemistry. V. Systematic Optimization of Exchange-Correlation Functionals. The Journal of Chemical Physics, 107, 8554-8560. https://doi.org/10.1063/1.475007

[23] Domingo, L.R., Rios-Gutierrez, M. and Perez, P. (2016) Applications of the Conceptual Density Functional Theory Indices to Organic Chemistry Reactivity. Molecules, 21, 748-770. https://doi.org/10.3390/molecules21060748

[24] Koch, W. and Holthausen, M.C. (2011) A Chemist's Guide to Density Functional Theory. 2nd Edition, Wiley-VCH, Hoboken.

[25] Frau, J., Flores-Holguín, N. and Glossman-Mitnik, D. (2019) Conceptual Density Functional Theory Study of the Chemical Reactivity Properties and Bioactivity Scores of the Leu-Enkephalin Opioid Peptide Neurotransmitter. Computational Molecular Bioscience, 9, 13-26. https://doi.org/10.4236/cmb.2019.91002

[26] Ashburn, B.O., Le, D.J. and Nishimura, C.K. (2018) Computational Analysis of Theacrine, a Purported Nootropic and Energy-Enhancing Nutritional Supplement. Computational Chemistry, 7, 27-37. https://doi.org/10.4236/cc.2019.71002

[27] Parr, R.G. and Pearson, R.G. (1983) Absolute Hardness: Companion Parameter to Absolute Electronegativity. Journal of the American Chemical Society, 105, 7512-7516. https://doi.org/10.1021/ja00364a005

[28] Parr, R.G. and Yang, W. (1989) Density Functional Theory of Atoms and Molecules. Oxford University Press, New York.

[29] Koopmans, T. (1934) Über die Zuordnung von Wellenfunktionen und Eigenwertenzu den Einzelnen Elektronen Eines Atoms. Physica, 1, 104-113.

https://doi.org/10.1016/S0031-8914(34)90011-2 
[30] Pearson, R.G. and Songstad, J. (1967) Application of the Principle of Hard and Soft Acids and Bases to Organic Chemistry. Journal of the American Chemical Society, 89, 1827-1836. https://doi.org/10.1021/ja00984a014

[31] Pearson, R.G. (1973) Hard and Soft Acids and Bases. Dowden, Hutchinson and Ross, Stroudsberg.

[32] Pearson, R.G. (1997) Chemical Hardness: Applications from Molecules to Solids. Wiley-VCH Verlag GMBH, Weinheim.

[33] Yang, W. and Parr, R.G. (1985) Hardness, Softness, and the Fukui Function in the Electronic Theory of Metals and Catalysis. Proceedings of the National Academy of Sciences of the United States of America, 82, 6723-6726.

https://doi.org/10.1073/pnas.82.20.6723

[34] Maynard, A.T., Huang, M., Rice, W.G. and Covel, D.G. (1998) Reactivity of the HIV-1 Nucleocapsid Protein p7 Zinc Finger Domains from the Perspective of Density-Functional Theory. Proceedings of the National Academy of Sciences of the United States of America, 95, 11578-11583. https://doi.org/10.1073/pnas.95.20.11578

[35] Parr, R.G., von Szentpaly, L. and Liu, S. (1999) Electrophilicity Index. Journal of the American Chemical Society, 121, 1922-1924. https://doi.org/10.1021/ja983494x

[36] Fukui, K. (1982) Role of Frontier Orbitals in Chemical Reactions. Science, 218, 747-754. https://doi.org/10.1126/science.218.4574.747

[37] Parr, R.G. and Yang, W. (1984) Density Functional Approach to the Frontier-Electron Theory of Chemical Reactivity. Journal of the American Chemical Society, 106, 4049-4050. https://doi.org/10.1021/ja00326a036

[38] Yang, W., Parr, R.G. and Pucci, R. (1984) Electron Density, Kohn-Sham Frontier Orbitals, and Fukui Functions, The Journal of Chemical Physics, 81, 2862-2863. https://doi.org/10.1063/1.447964

[39] Morell, C., Grand, A. and Toro-Labbe, A. (2005) New Dual Descriptor for Chemical Reactivity. The Journal of Physical Chemistry A, 109, 205-212. https://doi.org/10.1021/jp046577a

[40] Morell, C., Grand, A. and Toro-Labbe, A. (2016) New Theoretical Support for Using the $\mathrm{f}(\mathrm{r})$ Descriptor. Chemical Physics Letters, 425, 342-346. https://doi.org/10.1016/j.cplett.2006.05.003

[41] Martinez-Araya, J.I. (2014) Why Is the Dual Descriptor a More Accurate Local Reactivity Descriptor than Fukui Functions? Journal of Mathematical Chemistry, 53, 451-465. https://doi.org/10.1007/s10910-014-0437-7

[42] Shao, et al. (2006) Advances in Methods and Algorithms in a Modern Quantum Chemistry Program Package. Physical Chemistry Chemical Physics, 8, 3172-3191.

[43] Becke, A.D. (1988) Density-Functional Exchange-Energy Approximation with Correct Asymptotic Behavior. Physical Review A, 38, 3098-3100.

https://doi.org/10.1103/PhysRevA.38.3098

[44] Lee, C., Yang, W. and Parr, R.G. (1988) Development of the Colle-Salvetti Correlation-Energy Formula into a Functional of the Electron Density. Physical Review $B$, 37, 785-789. https://doi.org/10.1103/PhysRevB.37.785

[45] Nkungli, N.K., Ghogomu, J.N., Nogheu, L.N. and Gadre, S.R. (2015) DFT and TD-DFT Study of Bis[2-(5-Amino-[1,3,4]-Oxadiazol-2-yl)Phenol](Diaqua)M(II) Complexes $[\mathrm{M}=\mathrm{Cu}, \mathrm{Ni}$ and $\mathrm{Zn}]$ : Electronic Structures, Properties and Analyses. Computational Chemistry, 3, 29-44. https://doi.org/10.4236/cc.2015.33005

[46] Leo, A., Hansch, C. and Elkins, D. (1971) Partition Coefficients and Their Uses. Che- 
mical Reviews, 71, 525-616. https://doi.org/10.1021/cr60274a001

[47] Lipinski, C.A., Lombardo, F., Dominy, B.W. and Feeney, P.J. (2001) Experimental and Computational Approaches to Estimate Solubility and Permeability in Drug Discovery and Development Settings. Advanced Drug Delivery Reviews, 46, 3-26. https://doi.org/10.1016/S0169-409X(96)00423-1

[48] Lipinski, C.A. (2004) Lead- and Drug-Like Compounds: The Rule-of-Five Revolution. Drug Discovery Today: Technologies, 1, 337-341.

https://doi.org/10.1016/j.ddtec.2004.11.007 